УДК 622.831

\title{
ОЦЕНКА ГОРНО-ГЕОЛОГИЧЕСКИХ ФАКТОРОВ НА ТЕМПЫ ПРОВЕДЕНИЯ ВЫРАБОТОК И ОБЪЕМЫ ДОБЫЧИ НА СОВРЕМЕННЫХ ШАХТАХ
}

Варгольских Анастасия Анатольевна аспирант, инженер по горным работам $\mathrm{AO}$ «Распадская-Коксовая» Научный руководитель: Клишин Владимир Иванович д.т.н., проф. чл.-корр. РАН, директор Институт угля ФИЦ УУХ СО РАН

Аннотация: в статье представлены данные по объемам добычи и темпов проходки горных выработок на различных шахтах Томь-Усинского и Ерунаковского месторождения, произведен факторный анализ взаимосвязи горно-геологических условий на объемы добычи и темпы проходки горных выработок на пластах различной мощности.

Ключевые слова: факторный анализ, подготовительный забой, добычной забой, статистический метод, горно-геологические условия залегания пласта, коэффициент корреляции.

\section{ASSESSMENT OF MINING AND GEOLOGICAL FACTORS ON THE PACE OF WORKINGS AND PRODUCTION VOLUMES AT MODERN MINES}

\section{Vargolskikh Anastasia Anatolyevna Scientific adviser: Klishin Vladimir Ivanovich}

\begin{abstract}
: the article presents data on the volume of production and the rate of penetration of mining workings at various mines of the Tom-USINSKY and Yerunakovsky deposits, a factor analysis of the relationship of mining and geological conditions on the volume of production and the rate of penetration of mining workings on layers of various capacities.

Key words: factor analysis, preparatory slaughter, mining face, statistical method, mining and geological conditions of the formation, correlation coefficient.
\end{abstract}


При проектировании угледобывающих предприятий учитываются горно-геологические условия месторождения. В связи с этим актуальной является проблема оценки и ранжирования факторов по степени их влияния на эффективность подземной геотехнологии. По мере развития технологии угледобывающей промышленности в России $[1,2,3]$ и за рубежом $[4,5,6]$ понятие сложности горно-геологических условий подземной разработки угольных месторождений, достижений горной науки и практики периодически изменяются.

По результатам статистической обработки данных по пластам мощностью до 3,5 м и более проведено ранжирование наиболее значимых факторов, влияющих на эффективность работы добычных и подготовительных забоев.

Факторный анализ позволяет снизить размерность выборки, т.е. объединяет коррелирующие между собой переменные (признаки) в факторы, тем самым уменьшается размерность пространства, в котором проводится анализ.

Для факторного анализа используются шесть переменных:

- средняя добыча (т/сут.);

- средняя мощность пласта (м);

- средний угол падения пласта (град);

- средняя глубина разработки (м);

- число породных прослоев (ед);

- среднее значение темпов проведения выработки (м/сут).

Факторный анализ проведен в статистическом пакете SPSS Statistics 22.

Для выделения факторов используется метод главных компонент. Вращение компонент проводилось с помощью метода «варимакс» с нормализацией Кайзера.

Выделено три фактора с собственными значениями $\lambda>1$, которые объясняют 74,6\% совокупной дисперсии. На рисунке 1 приведен график собственных значений выделенных факторов. 


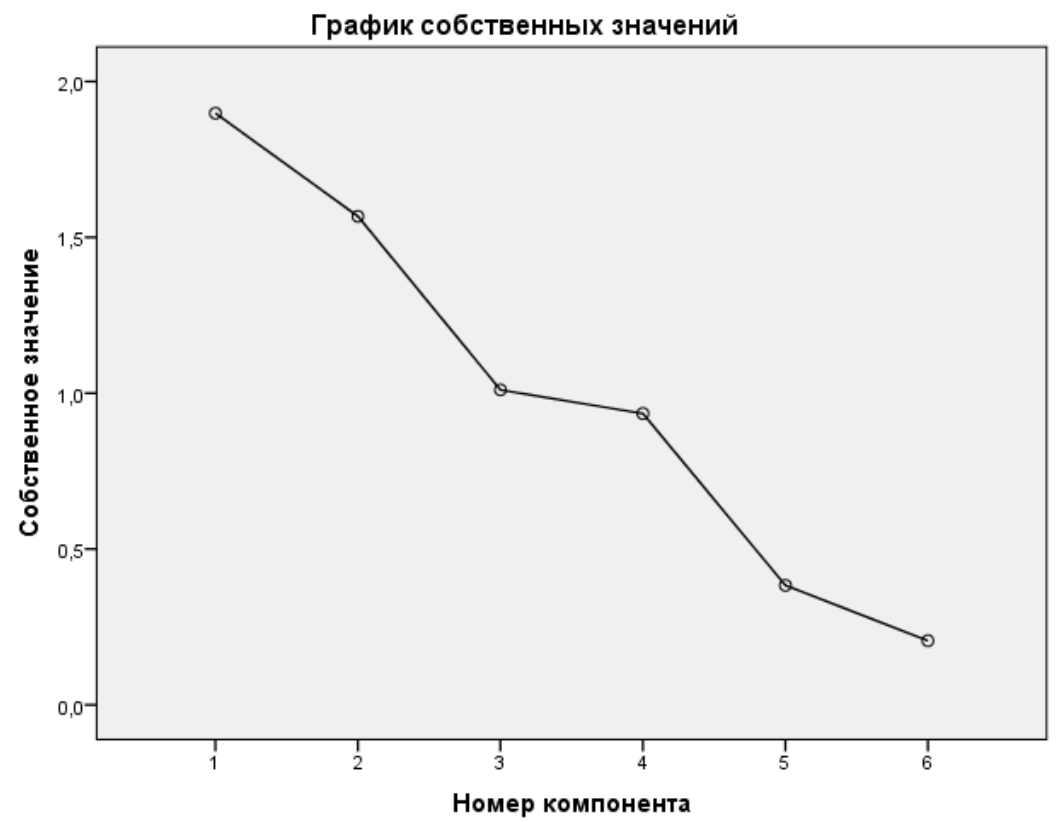

Рис. 1. График собственных значений компонент (факторов)

В таблице 1 приведена структура выделенных компонент, при этом отображены переменные, значения факторных нагрузок которых, составляет более 0,5 .

Таблица 1

\section{Повернутая матрица компонентов ${ }^{\mathrm{a}}$}

\begin{tabular}{|l|c|c|c|}
\hline \multirow{2}{*}{\multicolumn{1}{c|}{ Наименование }} & \multicolumn{2}{c|}{ Компонент } \\
\cline { 2 - 4 } & 1 & 2 & 3 \\
\hline Добыча, среднее число тонн в сутки, т/сут & & & 0,713 \\
\hline Мощность пласта, м & 0,881 & & \\
\hline Средний угол падения пласта, град & & 0,899 & \\
\hline Средняя глубина разработки пласта, м & & 0,816 & \\
\hline Число породных прослоев в пласте, ед & 0,907 & & \\
\hline $\begin{array}{l}\text { Среднее число метров в сутки при проведении } \\
\text { выработки, м/сут }\end{array}$ & & & 0,734 \\
\hline
\end{tabular}

Метод выделения факторов: метод главных компонент.

Метод вращения: варимакс с нормализацией Кайзера.

а. Вращение сошлось за 4 итераций.

Обозначить данные факторы можно следующим образом.

Фактор 1 - Средняя мощность пласта (м) и среднее количество породних прослоев в пласте (ед).

Фактор 2 - Средний угол падения пласта (град) и средняя глубина 
залегания пласта (м).

Фактор 3 - Средние объемы добычи (т/сут) и темпы проходки (м/сут).

В таблице 2 представлены коэффициенты корреляции Пирсона между факторами с учетом разбиения на группы $(\mathrm{m}<3.5$ м, m>3.5 м). Как видим из таблицы, значимая связь присутствует между 3 (средние объемы добычи (т/сут) и темпы проходки (м/сут)) и 1 (средняя мощность пласта (м) и среднее количество породних прослоев в пласте (ед)) факторами. Анализ коэффициентов корреляции Пирсона позволяет сделать вывод об отсутствии влияния 2 (средний угол падения пласта (град) и средняя глубина залегания пласта (м)) фактора на первый и третий. Поэтому переменные, в большей мере описывающие второй фактор, в дальнейшем можно исключить из факторного анализа.

Таблица 2

Значения парных коэффициентов корреляции Пирсона для факторов с учетом разделения на группы

\begin{tabular}{|c|c|c|c|c|c|}
\hline & \multicolumn{2}{|c|}{ Группы по мощности пласта } & $\begin{array}{c}\text { Фактор } 1 \\
\text { Средняя } \\
\text { мощность } \\
\text { пласта (м) } \\
\text { и среднее } \\
\text { количество } \\
\text { породних } \\
\text { прослоев в } \\
\text { пласте (ед) }\end{array}$ & $\begin{array}{c}\text { Фактор } 2 \\
\text { Средний } \\
\text { угол падения } \\
\text { пласта (град) } \\
\text { и средняя } \\
\text { глубина } \\
\text { залегания } \\
\text { пласта (м) }\end{array}$ & $\begin{array}{c}\text { Фактор } 3 \\
\text { Средние } \\
\text { объемы } \\
\text { добычи } \\
\text { (т/сут) и } \\
\text { темпы } \\
\text { проходки } \\
\text { (м/сут) }\end{array}$ \\
\hline \multirow[t]{6}{*}{$\begin{array}{l}\text { Пласт } \\
\mathrm{m}<3.5 \mathrm{M}\end{array}$} & \multirow{2}{*}{$\begin{array}{l}\text { Фактор } 1 \\
\text { Средняя мощность } \\
\text { пласта (м) и среднее } \\
\text { количество породних } \\
\text { прослоев в пласте (ед) }\end{array}$} & $\begin{array}{l}\text { Корреляция } \\
\text { Пирсона }\end{array}$ & 1 & $-0,049$ & 0,654 \\
\hline & & $\begin{array}{l}\text { Знач. } \\
\text { (двухсторонняя) }\end{array}$ & & 0,909 & 0,078 \\
\hline & \multirow{2}{*}{$\begin{array}{l}\text { Фактор } 2 \\
\text { Средний угол падения } \\
\text { пласта (град) и средняя } \\
\text { глубина залегания } \\
\text { пласта (м) }\end{array}$} & $\begin{array}{l}\text { Корреляция } \\
\text { Пирсона }\end{array}$ & $-0,049$ & 1 & 0,422 \\
\hline & & $\begin{array}{l}\text { Знач. } \\
\text { (двухсторонняя) }\end{array}$ & 0,909 & & 0,297 \\
\hline & \multirow{2}{*}{$\begin{array}{l}\text { Фактор } 3 \\
\text { Средние объемы } \\
\text { добычи (т/сут) и темпы } \\
\text { проходки (м/сут) }\end{array}$} & $\begin{array}{l}\text { Корреляция } \\
\text { Пирсона }\end{array}$ & 0,654 & 0,422 & 1 \\
\hline & & $\begin{array}{l}\text { Знач. } \\
\text { (двухсторонняя) }\end{array}$ & 0,078 & 0,297 & \\
\hline \multirow[t]{2}{*}{$\begin{array}{l}\text { Пласт } \\
\mathrm{m}>3.5 \mathrm{M}\end{array}$} & \multirow{2}{*}{$\begin{array}{l}\text { Фактор } 1 \\
\text { Средняя мощность } \\
\text { пласта (м) и среднее } \\
\text { количество породних } \\
\text { прослоев в пласте (ед) }\end{array}$} & $\begin{array}{l}\text { Корреляция } \\
\text { Пирсона }\end{array}$ & 1 & 0,069 & $-0,681$ \\
\hline & & $\begin{array}{l}\text { Знач. } \\
\text { (двухсторонняя) }\end{array}$ & & 0,897 & 0,136 \\
\hline
\end{tabular}


Продолжение таблицы 2

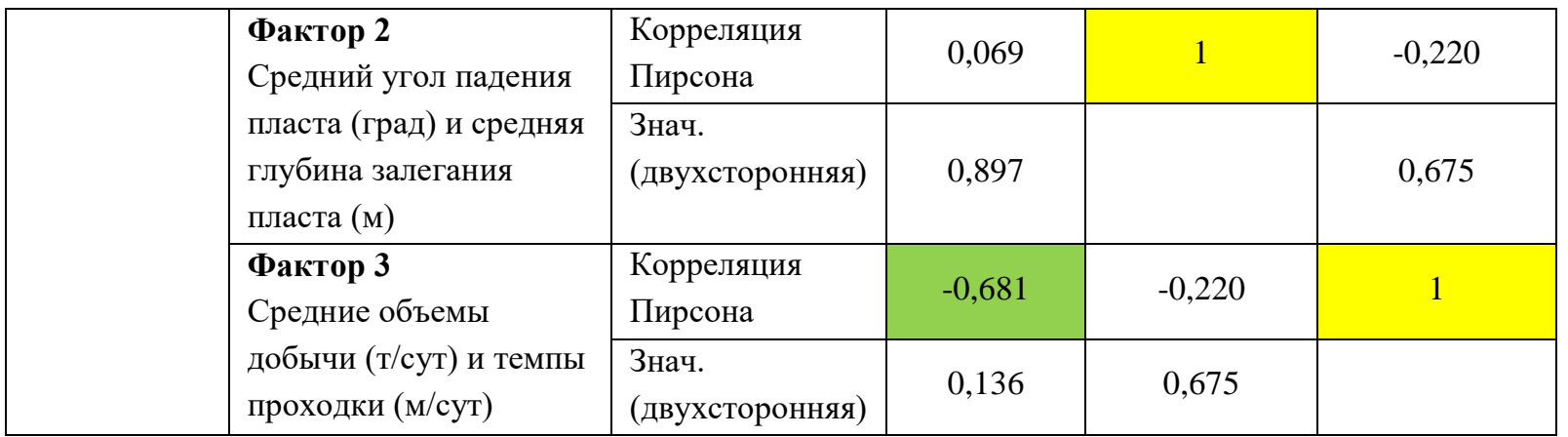

На рисунке 2 представлены облака рассеяния и парные регрессионные зависимости 3 и 1 факторов с учетом разделения пластов на группы по мощности - первая до 3,5 м, вторая более 3,5 м.

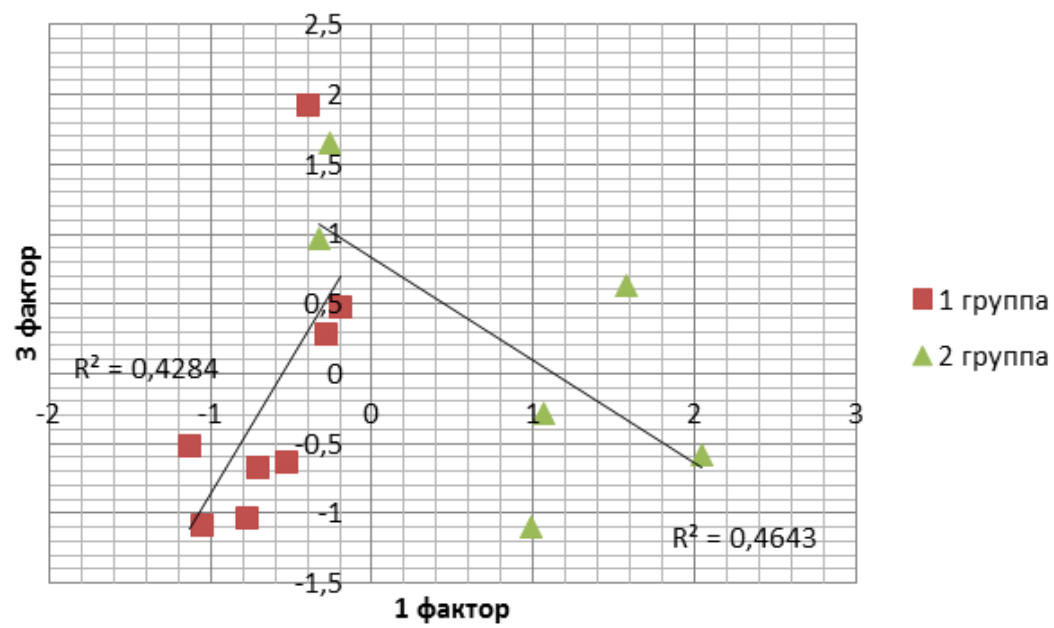

Рис. 2. Графики линейных регрессионных зависимостей 3 фактора от 1 с учетом разделения пластов на группы по мощности первая до 3,5 м, вторая более 3,5 м:

$$
\begin{array}{ll}
\text { первая группа } \mathrm{f3}=1,064+1,917 \cdot f 1 & R=0,654 ; \\
\text { вторая группа } f 3=0,825-0,734 \cdot f 1 & R=0,681 .
\end{array}
$$

Проведем еще раз факторный анализ методом главных компонент, для которого используем четыре переменных:

- средняя добыча (т/сут.);

- средняя мощность пласта (м);

- число породных прослоев (шт);

- среднее значение проходки (м/сут). 
Было выделено два фактора (собственные значения $\lambda>1$ ), которые объясняют 69,4\% совокупной дисперсии. На рисунке 3 приведен график собственных значений выделенных факторов.

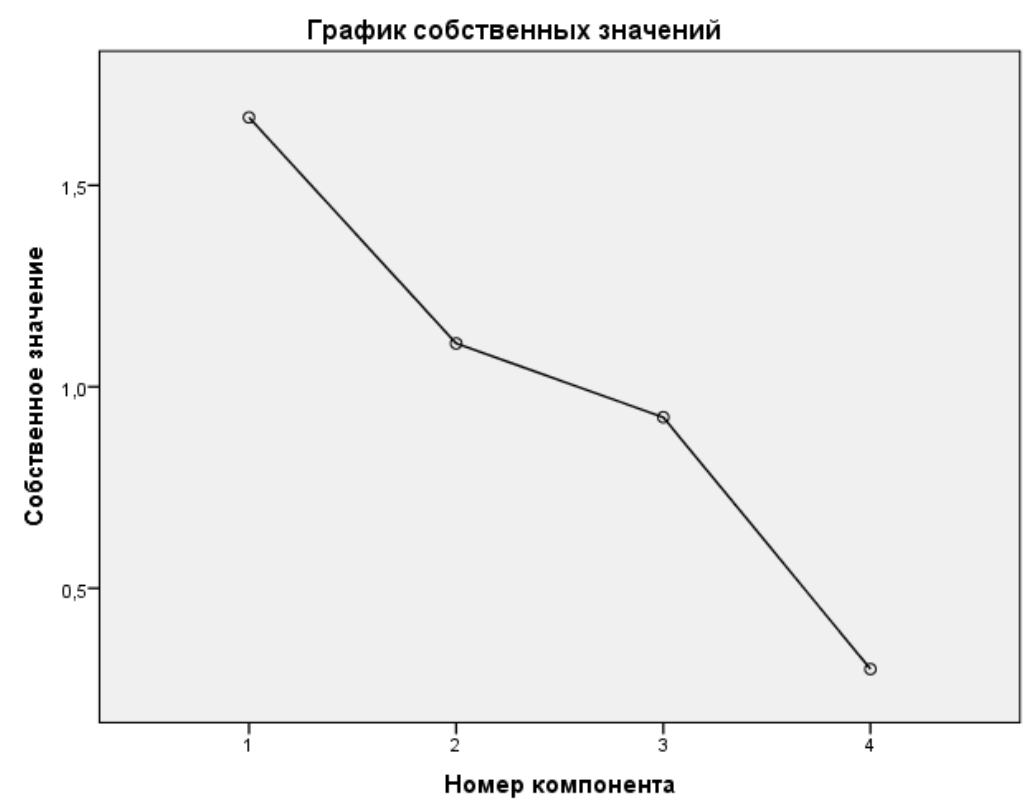

\section{Рис. 3. График собственных значений компонент (факторов)}

В таблице 3 приведена структура выделенных компонент, при этом отображены переменные, значения факторных нагрузок которых, составляет более 0,5 .

Таблица 3

Повернутая матрица компонентов ${ }^{\mathrm{a}}$

\begin{tabular}{|l|c|c|}
\hline \multirow{2}{*}{ Наименование } & \multicolumn{2}{|c|}{ Компонент } \\
\cline { 2 - 3 } & 1 & 2 \\
\hline Добыча, среднее число тонн в сутки, т/сут & & 0,773 \\
\hline Мощность пласта, м & 0,915 & \\
\hline Число породных прослоев, ед & 0,904 & \\
\hline Проходка, среднее число метров в сутки, м/сут & & 0,678 \\
\hline
\end{tabular}

Метод выделения факторов: метод главных компонент.

Метод вращения: варимакс с нормализацией Кайзера.

а. Вращение сошлось за 3 итераций.

Обозначить данные факторы можно следующим образом. 
Фактор 1 - средняя мощность пласта (м) и среднее количество породних прослоев (ед).

Фактор 2 - средние объемы добычи (т/сут) и темпы проведения выработки (м/сут).

В таблице 4 представлены коэффициенты корреляции Пирсона между факторами с учетом ранжирования на группы разделения пластов по мощности - первая до 3,5 м, вторая более 3,5 м.

Таблица 4

Значения парных коэффициентов корреляции Пирсона для 1 и 2 факторов с учетом разделения на группы

\begin{tabular}{|c|c|c|c|c|}
\hline \multicolumn{3}{|c|}{ Группы по мощности пласта } & $\begin{array}{c}\text { Фактор } 1 \\
\text { (средняя мощность } \\
\text { пласта (м) и } \\
\text { среднее количество } \\
\text { породних прослоев } \\
\text { (ед)) }\end{array}$ & $\begin{array}{c}\text { Фактор } 2 \\
\text { (средние объемы } \\
\text { добычи (т/сут) и } \\
\text { темпы проведения } \\
\text { выработки (м/сут)) }\end{array}$ \\
\hline \multirow[t]{4}{*}{$\begin{array}{l}\text { Пласт } \\
\mathrm{m}<3.5 \mathrm{M}\end{array}$} & \multirow{2}{*}{\begin{tabular}{l}
\multicolumn{1}{c}{ Фактор 1 } \\
(средняя мощность \\
пласта (м) и \\
среднее количество \\
породних прослоев \\
(ед))
\end{tabular}} & $\begin{array}{l}\text { Корреляция } \\
\text { Пирсона }\end{array}$ & 1 & 0,712 \\
\hline & & $\begin{array}{l}\text { Знач. } \\
\text { (двухсторонняя) }\end{array}$ & & 0,047 \\
\hline & \multirow{2}{*}{\begin{tabular}{l}
\multicolumn{1}{c}{ Фактор 2} \\
(средние объемы \\
добычи (т/сут) и \\
темпы проведения \\
выработки (м/сут)) \\
\end{tabular}} & $\begin{array}{l}\text { Корреляция } \\
\text { Пирсона }\end{array}$ & 0,712 & 1 \\
\hline & & $\begin{array}{l}\text { Знач. } \\
\text { (двухсторонняя) }\end{array}$ & 0,047 & \\
\hline \multirow[t]{4}{*}{$\begin{array}{l}\text { Пласт } \\
\mathrm{m}>3,5 \mathrm{M}\end{array}$} & \multirow{2}{*}{\begin{tabular}{l}
\multicolumn{1}{c}{ Фактор 1 } \\
(средняя мощность \\
пласта (м) и \\
среднее количество \\
породних прослоев \\
(ед))
\end{tabular}} & $\begin{array}{l}\text { Корреляция } \\
\text { Пирсона }\end{array}$ & 1 & $-0,732$ \\
\hline & & $\begin{array}{l}\text { Знач. } \\
\text { (двухсторонняя) }\end{array}$ & & 0,098 \\
\hline & \multirow{2}{*}{\begin{tabular}{l}
\multicolumn{1}{c}{ Фактор 2} \\
(средние объемы \\
добычи (т/сут) и \\
темпы проведения \\
выработки (м/сут))
\end{tabular}} & $\begin{array}{l}\text { Корреляция } \\
\text { Пирсона }\end{array}$ & $-0,732$ & 1 \\
\hline & & $\begin{array}{l}\text { Знач. } \\
\text { (двухсторонняя) }\end{array}$ & 0,098 & \\
\hline
\end{tabular}

На рисунке 5 представлены облака рассеяния и парные регрессионные зависимости 2 и 1 факторов с учетом групп. 


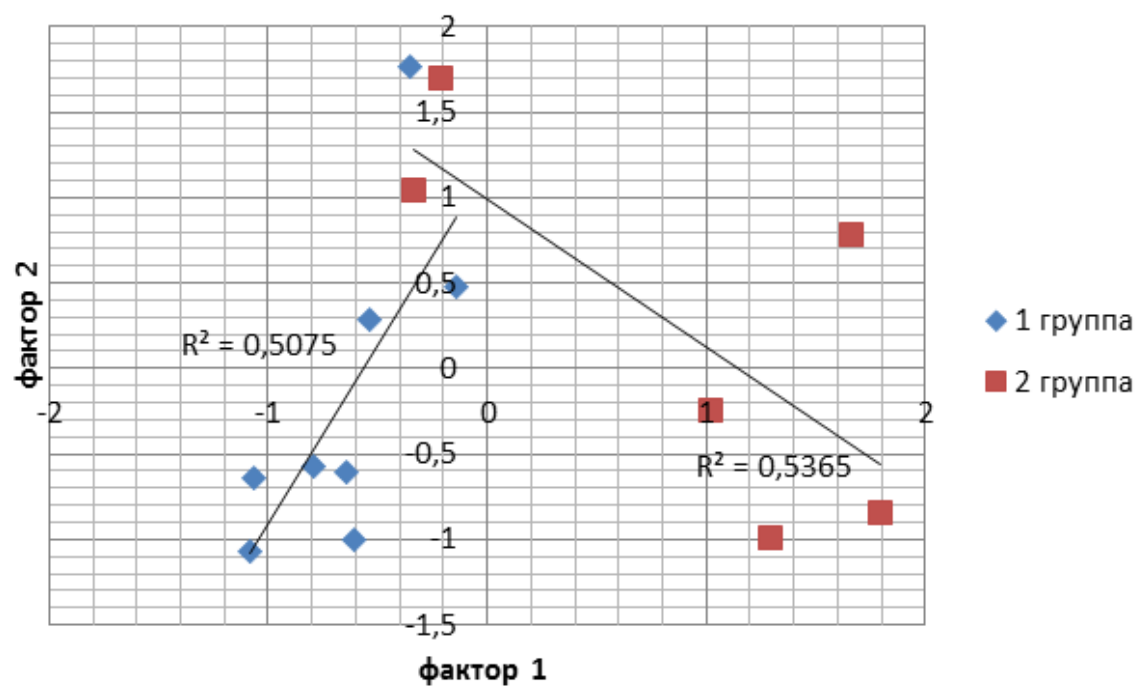

Рис. 5. Графики линейных регрессионных зависимостей 2 фактора от 1 с учетом групп: первая группа f2= 2,096 +1,190.f1 $\quad R=0,712$; вторая группа f2= 0,988 -0,864.f1 $\quad R=0,732$

Таким образом, по результатам проведенных исследований обоснованы следующие выводы и практические рекомендации:

- на пластах менее 3,5 м величина средних объемов добычи и средних темпов проведения выработки в сутки напрямую зависит от мощности разрабатываемого пласта и числа породных прослоев в нем;

- для пластов свыше 3,5 м данная зависимость является обратной;

- такие показатели как средний угол падения пласта (град) и средняя глубина залегания пласта (м) не влияют на темпы проведения выработки и объемы добычи.

При планировке пространственного положения очистных и подготовительных выработок необходимо учитывать данные факторы.

\section{Список литературы}

1. Коровкин Ю.А., Савченко П.Ф. Теория и практика длиннолавных систем. М.: Издательство «Горное дело» ООО «Киммерийский центр», 2012. $808 \mathrm{c}$.

2. Оценка факторов сложности условий ведения горных работ на современных угольных шахтах / Разумов Е.А. // Уголь. 2019. №10. С. 16-21.

3. Захаров В.Н., Забурдяев В.С., Артемьев В.Б. Углепородные массивы: прогноз устойчивости, риски, безопасность. М.: Издательство «Горное дело» 
ООО «Киммерийский центр», 2013. 280 с. (Библиотека горного инженера. Т. 3 «Подземные горные работы». Кн. 9).

4. Snopkowski R., Napieraj A., Sukiennik M. Method of the Assessment of the Influence of Longwall Effective Working Time Onto Obtained Mining Output // Archives of Mining Sciences. 2017. Vol. 61. N 4. P. 967-977.

5. Analysis and Optimization of Entry Stability in Underground Longwall Mining / Y. Gao, D. Liu, X. Zhang, M. He // Sustainability. 2017, Vol. 9. N 11. P. 2079-2088.

6. Stress Changes and Deformation Monitoring of Longwall Coal Pillars Located in Weak Ground / Bin Yu, Zhenyu Zhang, Tiejun Kuang, Jinrong Liu // Rock Mechanics and Rock Engineering. 2016. Vol. 49. Issue 8. P. 3293-3305.

7. Исаченко А.А., Фрянов В.Н., Петров А.А. Идентификация параметров признаков изменчивости геомассива по уровню добычи и промышленной безопасности выемочных участков угольных шахт // Вестник Забайкальского государственного университета. 2016. Т. 22. № 9. С. 4-14.

(C) А.А. Варгольских, 2021 